\title{
PREDICTORS OF POTENTIAL DRUG-DRUG INTERACTIONS AMONG DIABETIC HYPERTENSIVE ADULT OUTPATIENTS IN A KENYAN REFERRAL HOSPITAL
}

\author{
MAKITE SIMON LATI ${ }^{*}$, NYAMU GITONGA DAVID ${ }^{2 *}$, ROSALINE NJERI KINUTHIA ${ }^{3}$ \\ ${ }^{1 *}$ Clinical Pharmacist, Department of Pharmacy, Kangundo Level 4 Hospital, P. 0 Box 1002-90115, Kangundo, ${ }^{2 *}$ Department of \\ Pharmaceutics and Pharmacy Practice, University of Nairobi, P. O. Box 19676-00202, Nairobi, ${ }^{3}$ Department of Pharmacy, Kenyatta \\ National Hospital, P. O. Box 20723-00202 KNH, Nairobi \\ Email: makitesimonlati@gmail.com
}

Received: 20 Jun 2020, Revised and Accepted: 15 Oct 2020 ABSTRACT

Objective: To characterize the predictors of potential drug-drug interactions among adult diabetic hypertensive outpatients at Kenyatta National Hospital.

Methods: This cross-sectional study collected and analyzed data on potential drug interactions from 104 diabetic hypertensive outpatients (aged $\geq 18 \mathrm{y}$ ) at the Department of Endocrinology Outpatient Clinic of Kenyatta National Hospital from 1st May 2019 to 31st August 2019. The main outcome measure was the prevalence of potential drug-drug interactions and their predictors among the study population.

Results: There was a female preponderance (70.2\%). The mean age of the study participants was 61.6 y (SD \pm 10.8$)$. The prevalence of potential drug interactions was high at $57.7 \%$. The average number of drug interactions was one interacting pair per patient, with a majority of the prescriptions $(81.0 \%)$ having moderate drug-drug interactions. Patients receiving $>2$ drugs were almost three times more likely to have drug-drug interaction compared to those prescribeck 2 drugs (AOR=2.79; 95\% C I: 1.11-7.28); $p=0.029$ ). Participants who were at stage 4 of hypertension were 2.5 times more likely to have a drug-drug interaction compared to the other stages of hypertension (AOR=2.52; 95\% CI 1.31-4.89; $p=0.007$ )

Conclusion: Polypharmacy and stage 4 hypertension are independently associated with drug-drug interactions among patients with both diabetes and hypertension. Future studies should characterize the specific type of drug interactions and possible targets of minimization of drug-drug interactions.

Keywords: Potential drug-drug interactions, Diabetes, Hypertension, Antihypertensives

(C) 2020 The Authors. Published by Innovare Academic Sciences Pvt Ltd. This is an open access article under the CC BY license (http://creativecommons.org/licenses/by/4.0/) DOI: http://dx.doi.org/10.22159/ijpps.2020v12i12.38810. Journal homepage: https://innovareacademics.in/journals/index.php/ijpps.

\section{INTRODUCTION}

Diabetes mellitus (DM) and hypertension (HTN) are common comorbidities in both the developing and developed world. In 2015, the prevalence of diabetes mellitus was estimated at $9 \%$ globally, accounting for about half a million people with the disease and this is predicted to rise to $10.5 \%$ by 2040 [1]. In 2013, India and China had prevalence rates of about $10 \%$. High prevalence rates were also found in Egypt (16.8\%) and Mexico (12.6\%) which surpassed the rates of most developed countries, including Germany (8.2\%) and the USA $(9.2 \%)$ [2]

The prevalence of DM in Africa was approximately about $4 \%$ in 2015 and this is expected to reach $4.2 \%$ by 2040 [3]. Information from population-based studies in a systematic review has estimated the prevalence rate of diabetes mellitus to range from $1 \%$ among the Uganda's rural population to $12 \%$ in urban Kenya. In Kenya, the epidemiology of both hypertension and diabetes has not been studied to any great extent. However, health care facilities have provided anecdotal evidence suggesting that the incidence of DM and hypertension is on the rise [4]. The prevalence of hypertension is also on the rise. In 2008, the global prevalence of hypertension among adults was $40 \%$ with Africa having the highest prevalence at $46 \%[5]$.

The reasons for the global explosion in the prevalence of these two diseases, especially in Africa have been attributed to the aging populations, rapid urbanization, and increase of unhealthy lifestyles that have been witnessed in Africa during the last few decades [6] Diabetic patients have a two to fourfold likelihood of having cardiovascular disease compared to the general population [1]. Further, the prevalence of hypertension among DM patients is double that of the normal population [7]. Hypertension may also account for up to three-quarters of all cardiovascular disease events in people with diabetes. Studies have shown that hypertensive patients usually exhibit insulin resistance and have a greater risk of developing DM than are normotensive individuals [8]. Hypertension also accelerates the progression of diabetic complications, which include nephropathy, retinopathy, and neuropathy [9].

Management of these comorbid diseases involves several approaches. The American Diabetes Association (ADA) indicates lifestyle modification as the first management approach for these patients [10]. Diabetic hypertensives require combination pharmacotherapies to achieve targeted blood glucose as well as blood pressure goals [11]. The use of antihypertensive as well as metformin, other oral anti-diabetic drugs (OADs), and or with insulin are recommended if the glycemic control goals are not achieved with lifestyle changes alone [12]. Renin-angiotensin system (RAS) blockers such as Angiotensin Converting Enzyme inhibitors (ACEis) or Angiotensin Receptor Blockers (ARBs) are components of any drug regimen in the treatment of hypertension in diabetic patients (3). In addition, diuretics, $\beta$-blockers, and Calcium-Channel Blockers (CCBs) have also been reported to be clinically used [13].

Concomitant use of multiple agents has the potential to cause drugdrug interactions (DDIs), thereby producing undesirable effects [14] In an attempt to keep blood pressure and glucose levels controlled, multiple drugs subject the patient to polypharmacy, which may be irrational [15]. Furthermore, uninformed use of new drug therapies for any medical condition can be of concern to the patient due to an enhanced likelihood of experiencing drug-drug interactions and unperceived adverse drug events [16]. Studies have indicated that about $60 \%$ of patients fear that the prescribed medications may have drug interactions that will cause adverse drug reactions [17].

International studies have estimated that between 1\% and 21\% of adverse drug events leading to hospital admissions are a result of 
DDIs [18]. Patients with hypertension and diabetes are more likely to experience DDIs which is influenced by risk factors such as gender, advanced age, multiple drug therapy, and longer hospital stays. Studies have indicated that the potential DDIs for a particular antihypertensive or antidiabetic drug is dependent on individual physiological differences, the particular disease being managed, and the extent of exposure to other drugs [19]. Despite the above findings, there is scarcity of literature on potential drug-drug interactions for diabetic hypertensive patients in Sub-Saharan Africa [4]. The present study aimed at characterizing potential drug-drug interactions and their predictors among diabetic hypertensive adult outpatients at the largest teaching and referral hospital in East and Central Africa, Kenyatta National Hospital (KNH).

\section{MATERIALS AND METHODS}

\section{Participants and procedures}

This was a tertiary hospital-based cross-sectional study done among 104 adult patients between 1st May 2019 to 31st August 2019 at $\mathrm{KNH}$ which is the largest teaching and referral hospital in East and Central Africa. The study site was the Diabetic and Endocrinology outpatient clinic (DEOPC). Male and female adult's aged $\geq 18$ y were eligible if they had been diagnosed with comorbid HTN and DM and undergoing treatment at the DEOPC. The patients were also included if they were on at least one antihypertensive drug and one hypoglycemic agent. Pregnant women, patients with end-stage renal disease (ESRD) or liver disease, mentally ill patients and those with degenerative brain disease were excluded.

The main outcome variable for this study was the prevalence of potential DDIs among adult diabetic hypertensive patients. Available studies on drug-drug interactions among different populations indicated prevalence rates of DDIs varying between 92-96\% [16,
20]. Using these prevalence rates and the Cochran (1977) formula, the estimated minimum sample size was 86 participants. To cater for non-response, an additional $20 \%$ was added to make a total of 104 participants. Random sampling was employed until the sample size was accomplished.

Study approval was sought and granted by $\mathrm{KNH} /$ University of Nairobi-Ethics and Research Committee (KNH/UoN-ERC) reference number KNH-ERC/A/192. Authority to carry out the study was also granted by the Department of Research and Programs at KNH under reference number MED/42B/VOL.11/. Other procedures, including seeking the approvals from the Heads of Departments governing the study sites, were also observed prior to commencement of the research. Each of the eligible participants was explained the purpose of the study and taken through a detailed consenting process after which consent was requested.

\section{Data collection, entry and statistical analysis}

Data on patient demographics, clinical characteristics and drugs prescribed were extracted from patient medical records into predesigned data collection forms. Potential drug interactions were identified using the Micromedex® drug interaction checker [21]. Data was exported to STATA $\AA$ software version 13 for analysis. Categorical variables, including gender, number of potential DDIs per patient and severity of potential drug-drug interactions, were presented in the form of frequencies and percentages. Bivariate analysis was used to determine whether polypharmacy, use of a particular class of drug and duration of treatment were associated with the number of drug-drug interactions per patient. Multivariate logistic regression analysis was used to check if age, gender, and the number of prescribed drugs predicted the prevalence of DDIs. The odds ratios and their respective confidence interval (CI) were calculated for each variable. The level of significance was set at 0.05 .

\section{RESULTS}

Table 1: Sociodemographic characteristics of the study participants $(\mathrm{N}=104)$

\begin{tabular}{|c|c|c|c|}
\hline Variable & Characteristic & (n) & $(\%)$ \\
\hline \multicolumn{4}{|l|}{ Gender } \\
\hline & Male & 31 & 29.8 \\
\hline & Female & 73 & 70.2 \\
\hline \multicolumn{4}{|l|}{ Age category (years) } \\
\hline & $18-45 y$ & 7 & 6.7 \\
\hline & $46-59 y$ & 35 & 33.7 \\
\hline & $>59 y$ & 62 & 59.6 \\
\hline \multicolumn{4}{|l|}{ Body Mass Index } \\
\hline & Ideal (18.5-24.9) & 30 & 28.8 \\
\hline & Overweight (25.0-29.9) & 47 & 45.2 \\
\hline & Obese $(\geq 30.0)$ & 27 & 26.0 \\
\hline \multicolumn{4}{|l|}{ Marital status } \\
\hline & Single & 13 & 12.5 \\
\hline & Married & 68 & 65.4 \\
\hline & Separated & 1 & 1.0 \\
\hline & Widowed & 22 & 21.2 \\
\hline \multicolumn{4}{|l|}{ Religion } \\
\hline & Christians & 96 & 92.3 \\
\hline & Muslim & 8 & 7.7 \\
\hline \multicolumn{4}{|l|}{ Occupation } \\
\hline & Farmer & 15 & 14.4 \\
\hline & Business/Self-Employment & 26 & 25.0 \\
\hline & Formal Employment & 16 & 15.4 \\
\hline & Unemployed/retired & 47 & 45.2 \\
\hline \multirow[t]{4}{*}{ Level of education informal } & & 5 & 4.8 \\
\hline & Primary & 35 & 33.7 \\
\hline & Secondary & 54 & 51.9 \\
\hline & College/University & 10 & 9.6 \\
\hline
\end{tabular}

There was gender disparity as shown by a few males $(31,29.8 \%)$ compared to more females $(73,70.2 \%)$. Although the mean age of the participants was $61.6(\mathrm{SD} \pm 10.8)$ years, the elderly represented the largest group (59.6\%). Almost half $(47,45.2 \%)$ of the participants were overweight and over 95\% of the participants had at least a primary level of education (table 1).

The clinical characteristics of the study population are shown in table 2 . 
Table 2: Clinical characteristics of the study patients $(\mathrm{N}=104)$

\begin{tabular}{|c|c|c|c|}
\hline Variable characteristic & & Participants(n) & Percentage (\%) \\
\hline \multirow{3}{*}{ Diabetes } & Type 1 & 3 & 2.9 \\
\hline & Type 2 & 100 & 96.2 \\
\hline & Other & 1 & 0.9 \\
\hline \multirow[t]{5}{*}{ Duration of Diabetes } & $<1 \mathrm{y}$ & 10 & 9.6 \\
\hline & $1 \mathrm{y}$ & 4 & 3.8 \\
\hline & $2 y$ & 2 & 1.9 \\
\hline & $3 y$ & 3 & 2.9 \\
\hline & >3years & 85 & 81.8 \\
\hline \multirow[t]{4}{*}{ Stage of Hypertension } & Stage 1 & 98 & 94.3 \\
\hline & stage 2 & 35 & 33.7 \\
\hline & stage 3 & 18 & 17.3 \\
\hline & Unspecified & 6 & 5.7 \\
\hline \multirow[t]{5}{*}{ Duration of hypertension } & $<1 \mathrm{y}$ & 7 & 6.7 \\
\hline & $1 \mathrm{y}$ & 3 & 2.9 \\
\hline & $2 y$ & 2 & 1.9 \\
\hline & $3 \mathrm{y}$ & 4 & 3.8 \\
\hline & $>3 y$ & 88 & 84.7 \\
\hline \multirow[t]{2}{*}{ Presence of other co morbidities } & Yes & 53 & 51.0 \\
\hline & No & 51 & 49.0 \\
\hline
\end{tabular}

The majority (96.2\%) of the study population was suffering from type 2 diabetes and most of them had lived with the disease for more than three years (81.6\%). Additionally, the majority had stage 2 hypertension (43.3\%) and most had suffered from the disease for a similar duration, more than $3 \mathrm{y}$. Half of the study patients had at least an extra comorbidity apart from diabetes and hypertension (table 2).

The number, severity and onset of potential drug-drug interactions is shown in table 3 .

Table 3: Prevalence and pattern of potential drug-drug interactions $(\mathrm{N}=104)$

\begin{tabular}{llll}
\hline Variable & Characteristic & Participants (n) & Percentage (\%) \\
\hline DDI & Present & 60 & $\mathbf{5 7 . 7}$ \\
& Absent & 44 & 42.3 \\
Number of DDIs & One & 60 & $\mathbf{5 7 . 7}$ \\
& Two & 21 & 20.2 \\
\multirow{2}{*}{ Severity of DDIs } & Three & 3 & 2.9 \\
& Minor & 16 & 19.0 \\
& Moderate & 68 & $\mathbf{8 1 . 0}$ \\
\hline
\end{tabular}

Key: DDI=drug-drug interaction

A total of 84 drug-drug interactions were identified from the participants. About three quarters (81.0\%) of the prescriptions had moderate drug-drug interactions. More than half $(57.7 \%)$ of the study population had at least one drug-drug interaction though the average number of interactions was a unit. A fifth of the participants had two drug interactions (table 3).

Table 4 shows the associations between the participants' clinical characteristics and potential drug interactions.

The stage of hypertension was significantly associated with drugdrug interactions $(\mathrm{p}=0.031)$ (table 4$)$.
Table 5 shows the associations between particular drugs prescribed to patients and the presence or absence of drug-drug interactions.

Patients receiving more than two drugs were almost three times more likely to have DDI compared to those who were on two drugs or less (AOR=2.79; 95\% CI: 1.11-7.28); $p=0.029$ ). Participants who were at stage 4 of hypertension were 2.5 times more likely to have a DDI (AOR=2.52; 95\% CI 1.31-4.89; $p=0.007$ ). Although use of nifedipine and losartan was associated with the possibility of drugdrug interactions at bivariate analysis, this observation was lost on regression (table 6).

Table 4: Associations between clinical characteristics of the study participants and drug-drug interactions

\begin{tabular}{|c|c|c|c|c|}
\hline \multirow[t]{2}{*}{ Variable } & \multirow[t]{2}{*}{ Characteristic } & \multicolumn{3}{|c|}{ Presence of DDIs } \\
\hline & & Yes & No & p-value \\
\hline \multirow[t]{3}{*}{ Diabetes } & Type 1 & $1(33.3)$ & $2(66.7)$ & \\
\hline & Type 2 & $59(59)$ & $41(41)$ & 0.339 \\
\hline & Other & $0(0)$ & $1(100)$ & \\
\hline \multirow[t]{2}{*}{ Duration of diabetes } & $\leq 3$ years & $10(52.6)$ & $9(47.4)$ & \\
\hline & $>3 y$ & $50(58.8)$ & $35(41.2)$ & 0.742 \\
\hline \multirow[t]{2}{*}{ Hypertension } & Stage 1,2 and 3 & $55(56.1)$ & $43(43.9)$ & \\
\hline & Stage 4 & $5(83.3)$ & $1(16.7)$ & 0.031 \\
\hline \multirow[t]{2}{*}{ Duration of hypertension } & $\leq 3 \mathrm{y}$ & $6(37.5)$ & $10(62.5)$ & \\
\hline & $>3 y$ & $54(61.4)$ & $34(38.6)$ & 0.435 \\
\hline Presence of other & Yes & $33(62.3)$ & $20(37.7)$ & 0.223 \\
\hline Comorbidities & No & $27(52.9)$ & $24(47.1)$ & \\
\hline
\end{tabular}

Key: DDI-drug-drug interactions 
Table 5: Relationship between drugs prescribed and presence or absence of drug-drug interactions among the study participants

\begin{tabular}{|c|c|c|c|c|}
\hline \multirow[t]{2}{*}{ Variable } & \multirow[t]{2}{*}{ Characteristic } & \multicolumn{3}{|c|}{ Drug-drug interaction } \\
\hline & & Yes & No & p-value \\
\hline \multirow[t]{2}{*}{ Enalapril } & Yes & $17(73.9)$ & $6(26.1)$ & \\
\hline & No & $43(53.1)$ & $38(46.9)$ & 0.076 \\
\hline \multirow[t]{2}{*}{ Losartan } & Yes & $21(44.7)$ & $26(55.3)$ & \\
\hline & No & $39(68.4)$ & $18(31.6)$ & 0.014 \\
\hline \multirow[t]{2}{*}{ Hydrochlorothiazide } & Yes & $14(51.9)$ & $13(48.1)$ & \\
\hline & No & $46(59.7)$ & $31(40.3)$ & 0.796 \\
\hline \multirow[t]{2}{*}{ Furosemide } & Yes & $8(100)$ & $0(0)$ & \\
\hline & No & $52(54.2)$ & $4(45.8)$ & 0.011 \\
\hline \multirow[t]{2}{*}{ Nifedipine } & Yes & $17(89.5)$ & $2(10.5)$ & \\
\hline & & $43(50.6)$ & $42(49.4)$ & 0.002 \\
\hline \multirow[t]{2}{*}{ Amlodipine } & Yes & $16(53.3)$ & $14(46.7)$ & \\
\hline & No & $44(59.5)$ & $30(40.5)$ & 0.317 \\
\hline \multirow[t]{2}{*}{ Carvedilol } & Yes & $16(94.1)$ & $1(5.9)$ & \\
\hline & No & $44(50.6)$ & $43(49.4)$ & 0.001 \\
\hline \multirow[t]{2}{*}{ Methyldopa } & Yes & $0(0)$ & $1(100)$ & \\
\hline & No & $60(58.3)$ & $43(41.7)$ & 0.394 \\
\hline \multirow[t]{2}{*}{ Glibenclamide } & Yes & $5(21.7)$ & $18(78.3)$ & \\
\hline & No & $55(67.9)$ & $26(33.1)$ & 0.451 \\
\hline \multirow[t]{2}{*}{ Sitagliptin } & Yes & $6(54.5)$ & $5(45.5)$ & \\
\hline & No & $54(58.1)$ & $39(41.9)$ & 0.825 \\
\hline \multirow[t]{2}{*}{ Metformin } & Yes & $50(59.5)$ & $34(40.5)$ & \\
\hline & No & $10(50)$ & $10(50)$ & 0.443 \\
\hline
\end{tabular}

There were statistically significant associations between the presence of drug-drug interactions and use of losartan ( $\mathrm{p}=0.014)$, nifedipine $(\mathrm{p}=0.002)$ and carvedilol ( $\mathrm{p}=0.001$ ) (table 5). The independent predictors of DDIs on logistic regression are shown in table 6.

Table 6: Independent predictors of drug-drug interactions $(\mathrm{N}=104)$

\begin{tabular}{|c|c|c|c|c|}
\hline \multirow[t]{2}{*}{ Variable } & \multicolumn{2}{|l|}{ Bivariate analysis } & \multicolumn{2}{|c|}{ Multivariate analysis } \\
\hline & COR $(95 \% \mathrm{CI})$ & P-value & AOR (95\% CI) & P-value \\
\hline No. of drugs $(>2$ vs $\leq 2)$ & $2.12(1.15-3.92)$ & $0.020^{*}$ & $2.79(1.11-7.28)$ & 0.029 \\
\hline Stage of hypertension (4 vs 1 -3) & $2.63(1.50-4.68)$ & $0.002^{*}$ & $2.52(1.34-4.89)$ & 0.007 \\
\hline Use of nifedipine & $6.42(1.31-31.57)$ & $0.008^{*}$ & $1.45(0.65-3.28)$ & 0.451 \\
\hline Use of losartan & $4.60(0.99-21.36)$ & $0.005^{*}$ & $2.50(0.91-7.00)$ & 0.142 \\
\hline
\end{tabular}

Key: AOR=Adjusted Odds Ratio; CI=Confidence Interval; COR=Crude Odds Ratio; N=Sample, size; *statistically significant result.

\section{DISCUSSION}

This study has led to the characterization of prevalence and predictors of potential drug interactions among patients with both diabetes and hypertension. This study revealed a high prevalence rate of potential DDI at $57.7 \%$, with at least one DDI pair per patient. The prevalence rate contrasts findings from related local studies, which indicated a prevalence of $96 \%$ [17]. Although there are deviations in proportions probably due to different settings and methodologies, the one drug-drug interaction pair was cited to be the commonest among this patient population. In addition, $80.0 \%$ of the participants had moderate drug interactions, which corroborate with $79.2 \%$ from Guantai et al. [25]. Notably, the high likelihood of losartan, carvedilol, and nifedipine being implicated in drug-drug drug reaction could be attributed to their widespread prescription among antihypertensives in the study population.

Generally, the patients were of older age as commonly found with the two comorbidities [22] and the majority of participants had type 2 diabetes, which is the most common type [23]. Patients had lived with the comorbidities for more than three years, suggesting that they were already accustomed to the pharmacotherapy. The majority of patients were on more than two drugs, which corroborate other studies that have demonstrated that most patients with dual comorbidities are on multi-drug therapy [24].

Prescription of more than two drugs and stage 4 hypertension were independent predictors of DDIs. A similar observation was made in a study by Kim et al. [22], which indicated that patients on multidrug therapy and stage 4 hypertension were more likely to have drugdrug interactions. Obviously, patients in stage 4 hypertension are likely to be receiving multiple antihypertensives to control the blood pressure in addition to the regular antidiabetic medications.
Furthermore, studies have revealed that the management of hyperglycemia and stage 4 hypertension requires the use of multiple medications, which increase the probability of drug-drug interactions [26]. Moreover, patients with advanced stages of hypertension may require multiple drug therapies to control blood pressure compared to those with stages 1-3 of hypertension, which increases the likelihood of DDI.

\section{LIMITATIONS OF THE STUDY}

The study was limited to the characterization of the potential DDI between antihypertensives and antidiabetics, although patients may have been receiving other agents. However, it has provided useful insights for future co-prescribing of antidiabetics and antihypertensives. Additionally, the present study was done over a relatively short duration of time and therefore, though useful findings have been established, it could not establish what was occurring throughout the year.

\section{CONCLUSION}

The study established a high prevalence rate of moderate potential drug-drug interactions among diabetic hypertensive patients, which were significantly associated with stage 4 hypertension and the $>2$ prescribed drugs. Clinicians should be aware of the high potential for drug interactions among this patient population and cautiously prescribe medications that are less likely to cause DDIs. Future large cohort studies may be required to assess the specific type of potential drug interactions, clinical outcome and the potential targets for minimization of interactions.

\section{ACKNOWLEDGEMENT}

To all staff and patients at KNH DEOPC clinics for the immeasurable support during the study. 


\section{FUNDING}

This study was not funded

\section{AUTHORS CONTRIBUTIONS}

SM and DN conceptualized the idea. SM wrote the concept, collected and analyzed the data with the help of DN. DN assisted with proposal development, data analysis, and interpretation as well as writing the manuscript. RK reviewed and revised the manuscript. All authors approved the final manuscript for publication.

\section{CONFLICT OF INTERESTS}

Authors declare no conflict of interest.

\section{REFERENCES}

1. Petrie JR, Guzik TJ, Touyz RM. Diabetes, hypertension and cardiovascular disease: Clinical Insights Vascular Mechanisms 2018;34:575-84.

2. Seuring T, Archangelidi O, Suhrcke M. The economic costs of type 2 diabetes: a global systematic review. Pharmacoeconomics 2015;33:811-31.

3. Ogunsina MA, Anumah FO. Prevalence and correlates of hypertension and diabetes mellitus in an urban community in North-Western Nigeria. Pan Afr Med J 2018;8688:1-5.

4. Muchira J, Stuart Shor E, Kariuki J, Mukuna A, Ndigirigi I, Gakage L, et al. Distribution and characteristics of risk factors for cardiovascular-metabolic disease in a rural Kenyan community. Int J Afr Nursing Sci 2015;3:76-81.

5. Cham B, Scholes S, Fat LN, Badjie O, Mindell JS. Burden of hypertension in the Gambia: evidence from a national World Health Organization (WHO) STEP survey. Int J Epidemiol 2018;47:860-71.

6. Ker JA. Management issues in hypertensive diabetics. Medpharm Association 2011;53:144-9.

7. Seedat Y, Rayner B. The abridged South African hypertension guideline 2011. South African Family Practice 2012;54:111-6.

8. Mohan V, Seedat YK, Pradeepa R. The rising burden of diabetes and hypertension in Southeast Asian and African regions: need for effective strategies for prevention and control in primary health care settings. Int J Hypertension 2013;1-14. https://doi.org/10.1155/2013/409083

9. Marwa I, Gugu G, Mtshali G. Comorbidity of diabetes and hypertension and available management strategies in Eastern African Region. Journal of Nursing and Health Science; 2017. p. 1-9.

10. Emily P, Kelechi C, Krista L. Diabetic medications and polypharmacy. Diabetic Medications Polypharmacy Emily Richmond 2016;31:17-31.

11. Shanmugam S. Chapter-28 management of hypertension in diabetes. Diabetes Mellitus 2006;124-8.

12. Manikandan R, Nandamuri SSS, Logaraj M. Assessment of medication adherence among patients with hypertension and diabetes mellitus in urban field practice. Asian J Pharma Clin Res 2018;11:130-2.

13. The health of the people: the African regional health report. Brazzaville: World Health Organization, Regional Office for Africa; 2006.

14. Maharani DD, Syafhan NF, Hersunaryati Y. Drug-related problems in hospitalized geriatric patients with diabetes mellitus. Int J Appl Pharm 2018;10:142-8.

15. Puspitasari AW, Azizahwati A, Hidayat AR. Analysis of potential drug interaction on antihypertension drugs prescription in community health center of sukmajaya district in period of June-November 2015. Asian J Pharm Clin Res 2017;10:61-5.

16. Ofori Asenso R, Agyeman A. Irrational use of a medicines-a summary of key concepts. Pharmacy 2016;4:35-48.

17. Ogamba E. Diabetes and hypertension in kisii teaching and referral. MPharm Dissertation. University of Nairobi; 2016.

18. Martha S, Mateti U, Neerati V, Sivva D, Thiruthopu N. Assessment of drug-drug Interactions in hypertensive patients at a superspeciality hospital. Avicenna J Med 2015;5:29-35.

19. Huri HZ, Wee HF. Drug related problems in type 2 diabetes patients with 13 . Hypertension: a cross-sectional retrospective study. BMC Endocrine Disorders 2013;13:2-14.

20. Hazari MAH, Ram Reddy B, Uzma N, Santhosh Kumar B. Coagulation impairment in type 2 diabetes mellitus. Int J Diabetes Mellitus 2015;3:36-9.

21. Why Choose Micromedex?Truven Health Analytics. Available from:

https://truvenhealth.com/portals/0/assets/INTL_10276_0413_W hyChooseM DX.pdf. [Last accessed on 04 Mar 2019]

22. Kim MJ, Lim NK, Choi SJ, Park HY. Hypertension is an independent risk factor for type 2 diabetes: The Korean genome and epidemiology study. Hypertension Res Nat Publishing Group 2015;38:783-9.

23. Ayah R, Joshi MD, Wanjiru R, Njau EK, Otieno CF. A populationbased survey of prevalence of diabetes and correlates in an urban slum community in Nairobi, Kenya. BMC Public Health 2013;13:371-82.

24. Bhatta M. A prospective, cross-sectional study on cost and adherence of antidiabetic prescriptions at a tertiary care teaching hospital in South India. Value in Health; 2014. p. 17-9.

25. Guantai EM, Magot AA, Karimi PN, Maru SM, Nyamu DG. Identification and characterization of potential drug interactions in hypertensive patients in a Kenyan tertiary hospital Identification and characterization of potential drug interactions in hypertensive patients in a Kenyan tertiary hospital. Afr J Pharmacol Ther 2018;7:7-12.

26. Alwhaibi M, Balkhi B, Alhawassi TM, Alkofide H, Alduhaim N, Alabdulali R, et al. Polypharmacy among patients with diabetes: a cross-sectional retrospective study in a tertiary hospital in Saudi Arabia. BMJ Open 2018;8:1136-44 